\title{
Up-regulation of Pathogenesis-related Proteins in the Apoplast of Malus domestica after Application of a Non-pathogenic Bacterium
}

\author{
Sophia Kürkcüoglua ${ }^{\mathrm{a}}$ Markus Piotrowskib, and Achim E. Gau ${ }^{\mathrm{a}, *}$ \\ a Institut für Botanik, Universität Hannover, D-30419 Hannover, Germany. \\ Fax: (49)511-7623992. E-mail: achim.gau@botanik.uni-hannover.de \\ b Lehrstuhl für Pflanzenphysiologie, Ruhr-Universität Bochum, D-44780 Bochum, Germany \\ * Author for correspondence and reprint requests \\ Z. Naturforsch. 59c, 843-848 (2004); received July 9/August 4, 2004
}

The intercellular washing fluid (IWF) of Malus domestica cv. Holsteiner Cox before and after application of the non-pathogenic bacterium Pseudomonas fluorescens $\mathrm{Bk} 3$ to the leaves was investigated in a comparative manner. SDS-PAGE in combination with ESI Q-ToF mass spectrometry, and homology search in relevant data bases revealed the highly up-regulated expression of several pathogenesis-related plant proteins in the apoplast of the leaves treated with $P$. fluorescens. These proteins were $\beta$-1,3-glucanase, chitinase, thaumatin-like protein, ribonuclease-like protein, and a hevein-like protein. Moreover, a $9 \mathrm{kDa}$ non-specific lipid transfer protein was significantly reduced after the application of $P$. fluorescens. The possible relevance of a pre-treatment of apple cultivars with the non-pathogenic bacterium $P$. fluorescens $\mathrm{Bk} 3$, as an alternative method to the treatment with fungicides, for increasing the resistance of susceptible apple cultivars against an infection with the fungus Venturia inaequalis is discussed.

Key words: Apoplast, Biological Control, Pathogenesis-related Proteins

\section{Introduction}

The interaction of non-pathogenic microorganisms with its host plant is well characterized for the rhizosphere leading e.g. to enhanced root formation and as a consequence to a better nutrient uptake (Gozzo, 2003; Pieterse et al., 2001; van Loon et al., 1998). It has also been shown that treatment of tobacco with the non-pathogenic Pseudomonas fluorescens CHA0 in the rhizosphere leads to a higher resistance of the plant against tobacco necrosis virus (Maurhofer et al., 1994). In contrast to the well characterized interaction of root-colonizing bacteria with plants in the rhizosphere, only few details are known about the influcence of non-pathogenic bacteria in the phyllosphere of plants and its relation to the plant defense.

Apple trees of the species Malus domestica cultivar Holsteiner Cox become frequently infected with the fungus Venturia inaequalis leading to substantial damage of the leaves, blossoms, and fruits.

Abbreviations: ESI Q-ToF, electron spray ionisation quadrupole time of flight; IWF, intercellular washing fluid; PR, pathogenesis-related.
This process can be avoided by the application of fungicides. However, recently a substantial interest has developed in an alternative method by utilizing natural antagonists instead of excess fungicides. It is also well documented in the literature that in contrast to the apple cultivar Elstar, being damaged by $V$. inaequalis, the apple cultivar Remo is resistant to $V$. inaequalis (Fischer and Fischer, 1999). Our investigations have revealed that the resistant cultivar Remo constitutively expresses a number of pathogenesis-related proteins (PR proteins) in the apoplast (Gau et al., 2004). Moreover, preliminary results of our group have indicated that the non-pathogenic bacterium Pseudomonas fluorescens $\mathrm{Bk} 3$ when applied to the phyllosphere of the apple tree $M$. domestica cv. Holsteiner Cox can in part prevent the damage caused by $V$. inaequalis (Kucheryava et al., 1999; Fiss, 2001). Therefore, we asked the question whether the non-pathogenic $P$. fluorescens $\mathrm{Bk} 3$ might cause the induction of PR proteins. If this would be the case, this could be the reason for a higher resistance of the apple cultivar against the fungus $V$. inaequalis. 


\section{Materials and Methods}

Bacterial strain and growth conditions

Pseudomonas fluorescens $\mathrm{Bk} 3$ had been isolated in an orchard that was managed in the absence of chemicals for 15 years from Malus domestica cv. Holsteiner Cox from the leaf surface. This strain had shown in vitro an antagonistic effect to Venturia ineaequalis and was kindly provided by $\mathrm{G}$. Auling (Kucheryava et al., 1999). The strain was grown in Luria broth (LB) at $28^{\circ} \mathrm{C}$.

\section{Plant propagation and inoculation of $M$. domestica} with bacteria

M. domestica (cv. Holsteiner Cox) were cultivated as described by Gau et al. (2002). These sterile and genetically identical plants were transferrred to rooting media containing $1 \times$ Murashige \& Skoog medium including vitamins, $3 \%$ sucrose, $1.5 \mu \mathrm{M}$ indolebutyric acid and $0.7 \%$ plant agar. Four weeks after the transfer on rooting media five plants having a leaf fresh weight of approx. 0.7 to $1.3 \mathrm{~g}$ were sprayed with $1 \mathrm{ml}$ of an overnight culture of $P$. fluorescens Bk3 $\left(2 \times 10^{9}\right.$ cells) on both sides of the leaves. Subsequently, the plants were grown under a light/dark rhythm of $12 \mathrm{~h}$ at $24^{\circ} \mathrm{C}$.

\section{Isolation of intercellular washing fluid}

All leaves of the inoculated plants were selected for the isolation of apoplastic fluid. This was performed according to Gau et al. (2004). The leaves were cut off from the petiole and infiltrated for 5 min with PBS buffer under vacuum and were fixed between two transparent strips. The leaves were oriented with the cut area to the bottom of the centrifuge tube and centrifuged for $5 \mathrm{~min}$ at 50 $\times g$ in a Jouan AC50.10 rotor to remove the excess of liquid. The apoplastic fluid was collected by an additional centrifugation step for $15 \mathrm{~min}$ at $700 \times$ $g$ and finally stored at $-20^{\circ} \mathrm{C}$.

\section{Protein digestion and sequencing}

Proteins were excised after Coomassie brilliant blue staining from SDS-PAGE gels and digested according to Jensen et al. (1998). Peptide fragments were extracted from the gels by washing several times with the same volume of extraction solution $(50 \mu \mathrm{l}$ of a $1: 1$ mixture of $5 \%$ formic acid and acetonitrile). The extracted solutions were combined and concentrated with ZipTips C18
(Millipore). De novo sequencing was done on a quadrupole/time-of-flight hybrid mass spectrometer (Q-TOF2 Micromass, Waters, Manchester, United Kingdom) in positive-ion mode. Amino acid sequences were identified by homology search using the program PeptideSearch (EMBL, Heidelberg, Germany).

\section{Gel electrophoresis, silver staining, immunoblotting} and ECL-detection

SDS-PAGE and sample denaturation were carried out as described by Schägger and von Jagow (1987). Silver staining was done according to Blum et al. (1987). Immunoblotting was performed following the method of Towbin et al. (1979) using $0.45 \mu \mathrm{m}$ pore size nitrocellulose filters. Blots were blocked with $5 \%$ skim milk and incubated with selected antibodies against PR proteins (rabbit, 1:2000 dilution in milk), kindly provided by Dr. M. Legrand, IBMP, Strasbourg, France. The antibodies were detected by anti-rabbit-IgG from goat labelled with peroxidase (dilution 1:20000, Sigma, Munich, Germany) in an ECL-reaction containing $1.25 \mathrm{~mm}$ luminol, $0.2 \mathrm{~mm}$ coumaric acid, $0.01 \%$ $\mathrm{H}_{2} \mathrm{O}_{2}$, $100 \mathrm{~mm}$ Tris [tris(hydroxymethyl)aminomethane], pH 8.5. Chemiluminescence was detected with a Quantix CCD-camera (Photometrics, Kodak KAF 1401E chip) coupled with a Schneider/Kreuznach Xenon $0.95 / 25 \mathrm{~mm}$ objective and controlled by Lightview32 software (Photometrics) running on a Windows NT computer.

\section{Semi quantitative determination of transcript levels by RT-PCR}

Total RNA was isolated as described previously by Menhaj et al. (1999), treated with DNAse and subsequently converted to cDNA by Moloney $\mathrm{Mu}$ rine Leukemia virus reverse transcriptase as recommended by the manufacturer (Clontech, Palo Alto, California, USA). The cDNA was diluted $1: 10$ with water and $1 \mu \mathrm{l}$ was used directly for the PCR reaction with 1 unit Taq polymerase (Sigma, Munich, Germany) in the presence of $200 \mu \mathrm{M}$ dNTPs and $1 \mu \mathrm{M}$ of the respective primers, thaumatine-like fwd (5' atg tcg atg atg aag agc ca $3^{\prime}$ ), thaumatine-like rev $\left(5^{\prime}\right.$ tta tgg gca gaa agt aat gac g $\left.3^{\prime}\right), \beta$-1,3-glucanase fwd (5' tat gca ctt ttc aca gct cc $\left.3^{\prime}\right), \beta-1,3$-glucanase rev ( $5^{\prime}$ caa tgt ttc tca agc tct gg $\left.3^{\prime}\right)$, chitinase fwd ( $5^{\prime}$ atg get tca aag tcc aca gc $\left.3^{\prime}\right)$, chitinase rev ( $5^{\prime}$ cta gac atc att ctt gat $\left.3^{\prime}\right)$, elongation factor $1 \mathrm{a}$ fwd ( $5^{\prime}$ caa tgt gag agg tgt ggc 
aat c $\left.3^{\prime}\right)$, elongation factor 1 a rev ( $5^{\prime}$ gga gtg aag cag atg atc tgt $\left.\operatorname{tg} 3^{\prime}\right)$. Amplification was carried out for $3 \mathrm{~min}$ at $94^{\circ} \mathrm{C}$ followed by 35 cycles $(30 \mathrm{~s}$ at $94{ }^{\circ} \mathrm{C}$ primer specific annealing temperature for $1 \mathrm{~min}$ and elongation for $1.5 \mathrm{~min}$ at $72{ }^{\circ} \mathrm{C}$ ). The final extension was performed at $72^{\circ} \mathrm{C}$ for $3 \mathrm{~min}$. Amplification products were directly analyzed in a $1 \%$ agarose gel.

\section{Results and Discussion}

In this work the intercellular washing fluid (IWF) of $M$. domestica cv. Holsteiner Cox before and after application of $P$. fluorescens to the leaves was investigated in a comparative manner. For the analyses eight-week-old rooted apple plants of $M$. domestica $\mathrm{cv}$. Holsteiner Cox being genetically identical and grown under sterile conditions were used for isolation of the intercellular washing fluid (IWF) before and after treatment of the plant leaves with the non-pathogenic P. fluorescens Bk3. The IWF was isolated by the infiltration-centrifugation technique as described under Materials and Methods.

\section{Analysis of the IWF by SDS-PAGE}

The IWFs before and after application of the $P$. fluorescens $\mathrm{Bk} 3$ were subjected to SDS-PAGE and analysed 1,2, $5 \mathrm{~d}$ after application of the bacteria. The major differences, as shown in Fig. 1, are a substantial increase in proteins in the molecular

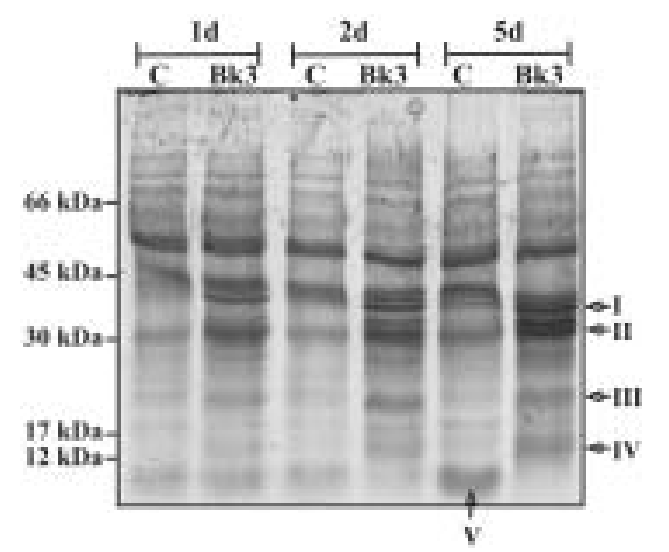

Fig. 1. SDS-PAGE of intercellular washing fluid (IWF) from $M$. domestica cv. Holsteiner Cox of control plants (C) and from plants after treatment with the non-pathogenic bacterium $P$. fluorescens $\mathrm{Bk} 3$. Each lane was loaded with $10 \mu \mathrm{g}$ protein. Numbered bands were sequenced by ESI Q-ToF mass spectrometry. mass range of 45 to $30 \mathrm{kDa}$ (bands I, II, III, and IV) and a substantial decrease of a $9 \mathrm{kDa}$ protein (band V).

\section{Protein digestion and sequencing}

Some of the proteins being increased or decreased by the treatment of $M$. domestica cv. Holsteiner Cox with $P$. fluorescens Bk3 were excised from the gel and digested with trypsin. The obtained peptide fragments were submitted to de novo sequencing on a quadrupole/time-of-flight hybrid mass spectrometer as described in Materials and Methods. For identification of the amino acid sequences the program PeptideSearch (EMBL) was used. A summary of the derived amino acid sequences and the identification of these polypeptides are given in Table I. Four bands could be identified as representing the following plant proteins: Band I representing $\beta$ 1,3-glucanase, band III representing ribonucleaselike PR-10b, band IV representing hevein-like protein PR-4b that also belongs to the group of chitinases, and band $\mathrm{V}$ representing a non-specific lipid transfer protein (ns-LTP). For band II the sequences suggested homologies to a thaumatin-like protein or an endochitinase. All identified polypeptides of the $P$. fluorescens Bk3 treated leaves from the cultivar Holsteiner Cox belong to the class of PR proteins in plants.

Three of the up-regulated proteins belong to carbohydrate or nucleic acid degrading enzymes being a glucanase (PR-2 group), chitinase (PR-3, 4, 8 or 11 group), and ribonuclease (PR-10 group). The likewise up-regulated thaumatin-like protein belongs to the PR-5 family which exhibits anti-fungal action (Datta and Muthukrishnan, 1999). In contrast to the up-regulation of these four PR proteins, the non-specific lipid transfer protein decreases after the treatment of leaves with $P$. fluorescens $\mathrm{Bk} 3$. It might be relevant to mention that we previously observed a decrease of this ns-LTP after the infection of the susceptible cv. Elstar with $V$. inaequalis (Gau et al., 2004). This might point to a functional role of this protein in the recognition and defense of pathogens.

Investigation of the transcript and protein level of $\beta$-1,3-glucanase, thaumatin-like protein, and chitinase

For additional verification of the increase of three of the above identified PR proteins RT-PCR 


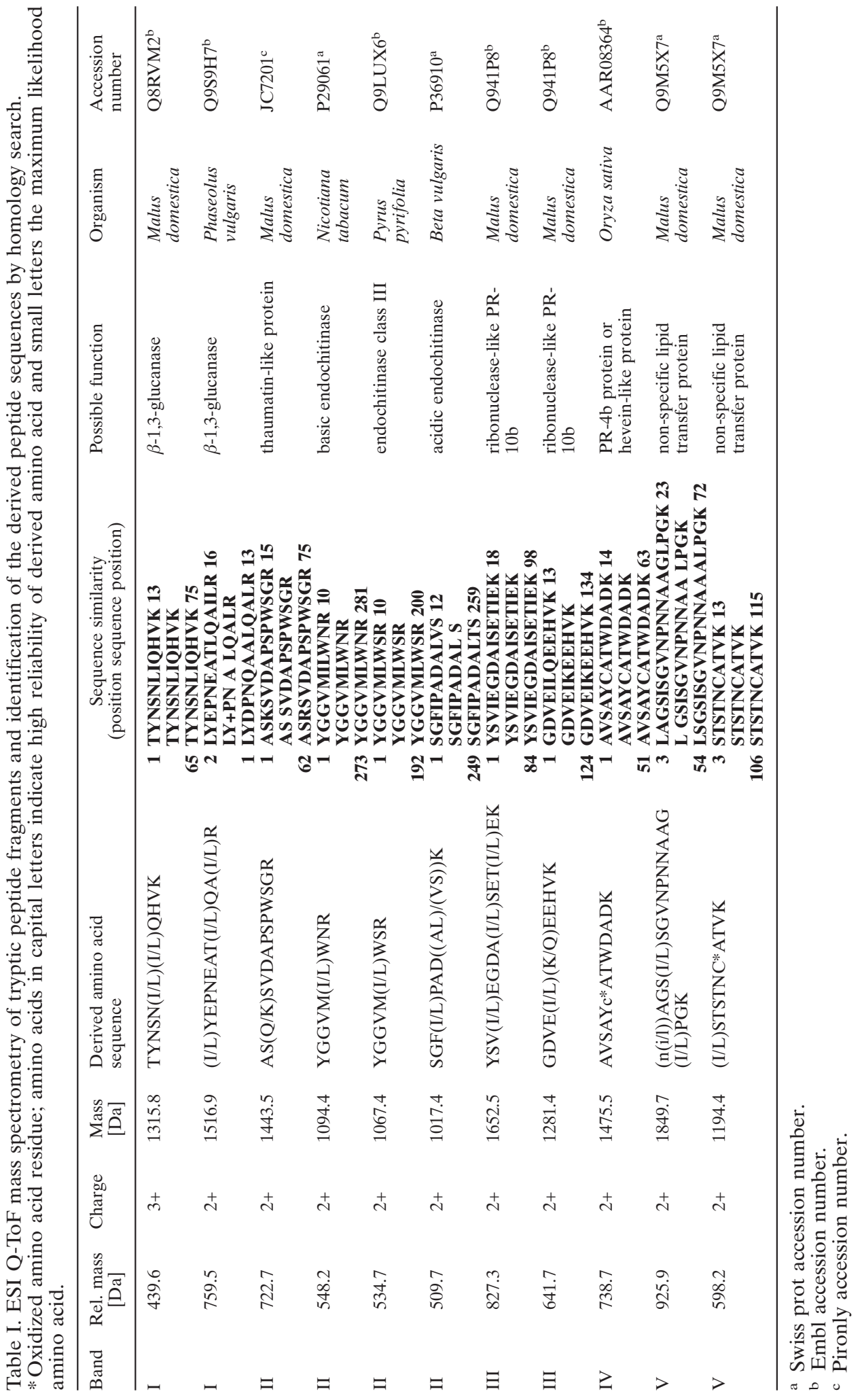




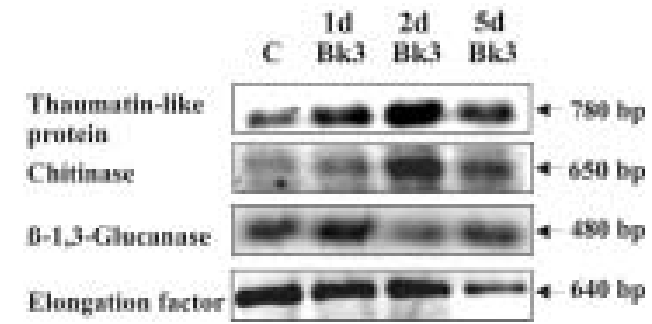

Fig. 2. Semiquantitative determination of selected PR genes by RT-PCR. RT-PCR was performed by using $1 \mu \mathrm{g}$ of total RNA isolated from leaves of $M$. domestica $\mathrm{cv}$. Holsteiner Cox and treated with DNAse. The M. domestica cv. Holsteiner Cox plants were treated for 1,2 and $5 \mathrm{~d}$ with $P$. fluorescens $\mathrm{Bk} 3$. C: Mock inoculation; $1 \mathrm{~d}$ Bk3: $1 \mathrm{~d}$ after application of $P$. fluorescens $\mathrm{Bk} 3$; $2 \mathrm{~d} \mathrm{Bk3 \text {: }}$ $2 \mathrm{~d}$ after application of $P$. fluorescens $\mathrm{Bk} 3 ; 5 \mathrm{~d} \mathrm{Bk} 3: 5 \mathrm{~d}$ after application of $P$. fluorescens Bk3.

and Western blotting were performed. RT-PR showed significant increases in the transcript level of the thaumatin-like protein and chitinase, while the increase of $\beta$-1,3-glucanase was less significant. This transcript level was already high in the control (Fig. 2). By using the corresponding antisera, it could be demonstrated that all three proteins strongly increased in the IWF of the treated leaves (Fig. 3). The major difference in the protein expression pattern of the three investigated proteins was that the protein level of the thaumatin-like protein and the $\beta$-1,3-glucanase was much higher on the fifth day as compared to the first or second day, while the chitinase protein level was as high on the first as on the fifth day. As expected, the increase of the transcript level for the thaumatinlike protein and the chitinase proceeded the increase in the protein level. In case of the $\beta-1,3-$

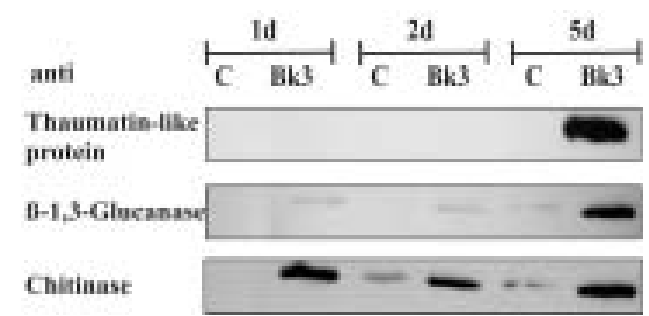

Fig. 3. Immunological detection of three PR proteins in the apoplastic fluid of $M$. domestica cv. Holsteiner Cox after treatment with $P$. fluorescens Bk3. Each lane was loaded with $10 \mu \mathrm{g}$ proteins and detection was done with the anti-thaumatin (dilution 1:2000), anti- $\beta$-1,3-glucanase (dilution 1:2000) and anti-chitinase (dilution $1: 2000)$. glucanase, it is relevant to mention that the transcript level was already high in the control. However, the chitinase protein level was clearly higher in the IWF of the treated leaves than in the untreated leaves - suggesting a translation control.

\section{Concluding remarks}

It is well documented in the literature that pathogenic bacteria induce in plants the expression of a substantial number of PR proteins which include carbohydrate, protein, nucleic acid, and lipid degrading enzymes, such as chitinases/glucanases, proteases, ribonucleases, or lipases (Datta and Muthukrishnan, 1999). Our results show that the non-pathogenic bacterium $P$. fluorescens $\mathrm{Bk} 3$ also causes the induction of such enzymes, as e.g. chitinase, $\beta$-1,3-glucanase and ribonuclease in the apple cultivar Holsteiner Cox after its application to the leaf surface. For the interpretation of the meaning of these results, two additional observations are relevant. Firstly, it has been shown that the pre-treatment of susceptible apple cultivars with bacterium $P$. fluorescens $\mathrm{Bk} 3$ makes the plants more resistant to infection by the fungus V. inaequalis (Kucheryava et al., 1999; Fiss, 2001). Secondly, in the apoplast of the cultivar Remo which is more resistant to the infection by $V$. inaequalis, a number of PR proteins are constitutively expressed (Gau et al., 2004). On the basis of these observations, the here presented results could be interpreted by suggesting that a pre-treatment of apple cultivars with $P$. fluorescens $\mathrm{Bk} 3$ leads to a higher resistance against infection by $V$. inaequalis due to the fact that PR proteins have become expressed before the infection with the fungus. Such a pre-treatment of apple cultivars with non-pathogenic bacteria can eventually replace excessive treatment of apple trees with fungicides.

In general, it can be stated that the protection of crop plants by induction of pathogenesis-related proteins caused by the application of non-pathogenic antagonists in the phyllosphere may become an alternative method to the chemical control of plant diseases.

\section{Acknowledgements}

S. K. expresses her gratitude to the Deutsche Bundesstiftung Umwelt for financial support. For providing antibodies against PR proteins $(\beta-1,3-$ glucanase, chitinase and thaumatin-like protein) we are very thankful to Dr. M. Legrand, (IBMP, 
Strasbourg, France) and for her excellent technical assistance especially with the cultivation and propagation of the plant material we are deeply grate-

Blum H., Beier H., and Gross H. J. (1987), Improved silver staining of plant proteins RNA and DNA in polyacrylamide gels. Electrophoresis 8, 93-99.

Datta S. K. and Muthukrishnan S. (1999), PathogenesisRelated Proteins in Plants. CRC Press, Boca Raton, London, New York, Washington D. C.

Fischer M. and Fischer C. (1999), Evaluation of Malus species and cultivars at the Fruit Genebank DresdenPillnitz and its use for apple resistance breeding. Genetic-Resources-and-Crop-Evolution 46, 235-241.

Fiss M. (2001), Evaluation of epiphytic antagonists in the biological control of Venturia inaequalis. PhD Thesis, University of Hannover.

Gau A. E., Dietrich C., and Kloppstech K. (2002), Noninvasive determination of plant associated bacteria in the phyllosphere of plants. Environ. Microbiol. 4, $744-752$.

Gau A. E., Koutb M., Piotrowski M., and Kloppstech K. (2004), Accumulation of pathogenesis-related proteins in the apoplast of a susceptible cultivar of apple (Malus domestica cv. Elstar) after infection by Venturia inaequalis and constitutive expression of $\mathrm{PR}$ genes in the resistant cultivar Remo. Eur. J. Plant Pathol. 110, $703-711$.

Gozzo F. (2003), Systemic acquired resistance in crop protection: from nature to chemical approach. J. Agric. Food Chem. 51, 4487-4503.

Jensen O. N., Wilm M., Schevchenko A., and Mann M. (1998), Sample preparation methods for mass spectrometric peptide mapping directly from 2-D gels. In: 2-D Proteome Analysis Protocols, Methods in Molecular Biology, vol. 112 (Link A. J., ed.). Humana Press, Inc., Totowa, N. J., pp. 513-530. ful to Mrs. J. Lensing. The financial support and many helpful discussions by Prof. Dr. K. Kloppstech are gratefully acknowledged.
Kucheryava N., Fiss M., Auling G., and Kroppenstedt R. M. (1999), Isolation and characterization of epiphytic bacteria from the phyllosphere of apple, antagonistic in vitro to Venturia inaequalis, the causal agent of apple scab. System. Appl. Microbiol. 22, 472478.

Maurhofer M., Hase C., Meuwly J. P., Métreaux J. P., and Défago G. (1994), Induction of systemic resistance of tobacco to tobacco necrosis virus by root-colonizing Pseudomonas fluorescens strain CHA0: influence of the gacA gene and of pyoverdine production. Phytopathology 84, 139-146.

Menhaj A. R., Mishra S. K., Bezhani S., and Kloppstech K. (1999), Posttranscriptional control in the expression of the genes coding for high-light-regulated HL2 proteins. Planta 209, 406-413.

Pieterse C. M. J., van Pelt J. A., van Wees S. C. M., Ton J., Léon-Kloosterziel K. M., Keurentjes J. J. B., Verhagen B. W. M., and Knoester, M. (2001), Rhizobacteriamediated induced systemic resistance: triggering, signalling and expression. Eur. J. Plant Pathol. 107, 5161.

Schägger H. and von Jagow G. (1987), Tricine-sodium dodecyl sulfate-polyacrylamide gel electrophoresis for the separation of proteins in the range from 1 to 100 kDa. Anal. Biochem. 166, 368-379.

Towbin H., Staehelin T., and Gordon J. (1979), Electrophoretic transfer of proteins from polyacrylamide gels to nitrocellulose sheets: procedure and some applications. Proc. Natl. Acad. Sci. USA 76, 4350-4354.

van Loon L. C., Bakker P. A. H. M., and Pieterse C. M. J. (1998), Systemic resistance induced by rhizosphere bacteria. Annu. Rev. Phytopathol. 36, 453-483. 